\title{
The association of diet and other lifestyle factors with the onset of overactive bladder: a longitudinal study in men
}

\author{
Helen M Dallosso*, Ruth J Matthews, Catherine W McGrother, Madeleine MK Donaldson, \\ Chris Shaw and the Leicestershire MRC Incontinence Study Group \\ Department of Health Sciences, University of Leicester, 22-28 Princess Road West, Leicester LE 1 6TP, UK
}

Submitted 27 November 2003: Accepted 31 March 2004

\begin{abstract}
Objective: To investigate associations between diet and non-dietary lifestyle factors and the onset of overactive bladder (OAB) in men.

Subjects: Random sample of community-dwelling men aged 40 years plus.

Design and methods: Baseline data on urinary symptoms and diet were collected from

5454 men using a postal questionnaire and a food-frequency questionnaire. Followup data on urinary symptoms were collected from 4887 men in a postal survey one year later. Logistic regression analysis was used to investigate diet and lifestyle factors associated with onset of $\mathrm{OAB}$ in the men without $\mathrm{OAB}$ at baseline.

Results: There was a highly significant negative association between beer intake at baseline and subsequent $\mathrm{OAB}$ onset $(P=0.001)$, with reduced risk at all levels of intake compared with those who seldom/never drank beer. Adjustment for total alcohol intake $\left(\mathrm{g}\right.$ ethanol $\left.\mathrm{day}^{-1}\right)$ reduced the significance of the association $(P=0.02)$. None of the food groups studied was associated with OAB onset, with the possible exception of potatoes $(P=0.05)$, which showed an increased risk of onset at the highest level of consumption. Physical activity, smoking and obesity were not significantly associated.

Conclusions: While most diet and lifestyle factors were not associated with $\mathrm{OAB}$ onset, the evidence from this prospective longitudinal study suggests that beer may have a protective role in the development of $\mathrm{OAB}$. This could be due to a nonalcoholic ingredient as well as the alcohol content.
\end{abstract}

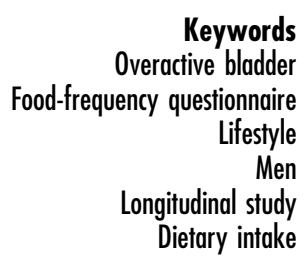

Overactive bladder (OAB) is classified as a symptom syndrome suggestive of lower urinary tract dysfunction by the International Continence Society ${ }^{1}$ and is thought to be due mainly to detrusor overactivity during bladder filling ${ }^{2}$. The detrusor is the muscular coat of the bladder and allows bladder filling to occur with little or no change in pressure. Detrusor overactivity is characterised by involuntary contractions of the detrusor during the filling phase that may be spontaneous or provoked. The symptoms of OAB include urinary urgency (with or without urge incontinence and usually associated with nocturia and a high frequency of micturition). The origin of detrusor overactivity may be neurogenic, with a variety of neurological causes ${ }^{3}$; some of these may be related to diet, for example neuropathies resulting from vitamin $B_{12}$ deficiency ${ }^{4}$. Another proposed pathological mechanism is myogenic bladder overactivity ${ }^{5}$. Acute or chronic effects of dietary components on the contractility of the detrusor muscle may be important.

Several studies have investigated the association of nondietary lifestyle factors such as smoking, alcohol and physical activity with incontinence and other urinary storage symptoms, although the results are conflicting ${ }^{6-9}$. No studies have looked at diet. Identification of lifestyle factors associated with $\mathrm{OAB}$ onset in a longitudinal study may help understand the mechanisms in its aetiology and be useful in the development of behavioural strategies for its treatment and prevention.

In an earlier publication we reported on diet and nondietary lifestyle factors associated with $\mathrm{OAB}$ onset over one year in women ${ }^{10}$. The present paper reports the results of the equivalent analysis in men.

\section{Methods}

\section{Sample and study outline}

The study was part of the Leicestershire MRC Incontinence Study of the prevalence and incidence of incontinence and other lower urinary tract symptoms in community-dwelling men and women aged 40 years plus ${ }^{10}$.

A random sample of 19355 men aged 40 years plus was drawn from the Leicestershire Health Authority's lists of 108 general practices. Men living in residential or nursing homes were excluded. A baseline postal questionnaire 
was mailed in October 1998 and two reminders sent to non-responders at 4-week intervals. Of those mailed, 1797 (9.3\%) were not eligible for the sample (moved from study area or deceased) and 10614 returned the questionnaire (60.5\% of the eligible sample). A food-frequency questionnaire (FFQ) was sent to responders to the first and second mailings $(n=8963)$, excluding those of South Asian origin who have very different dietary habits to the population in which the questionnaire was validated. The FFQ was completed by 5454 men (response rate 60.9\%). A year later a follow-up postal questionnaire was sent to all FFQ responders, with two reminders sent to nonresponders. A total of 4887 follow-up questionnaires were returned (response rate $89.7 \%$ ).

Response rate to the baseline questionnaire increased with age until the 80 year plus group when it decreased and responders were older than non-responders (median age: 58 vs. 56 years, $P<0.001$ ). An in-depth study into non-response at baseline showed little indication of nonresponse bias in the reporting of urinary symptoms at this stage $^{11}$. Response rates to both the FFQ and the follow-up questionnaire also increased with age until the top age group, and again responders were older than nonresponders. After adjustment for age, men with poor general health at baseline were less likely to respond to the FFQ (odds ratio (OR) 0.69; 95\% confidence interval (CI) $0.63-0.77$ ) as well as to the follow-up questionnaire (OR 0.76; 95\% CI 0.62-0.93).

\section{Baseline and follow-up questionnaires}

The baseline and follow-up questionnaires contained questions on urinary symptoms experienced over the previous 12 months. The questions were developed for the study $^{12}$ in line with recommended standards ${ }^{1}$. The International Continence Society defines the overactive bladder syndrome as "urgency with or without urge incontinence, usually with frequency and nocturia' ${ }^{, 1}$. For the purposes of the present study, OAB was defined as one or both of the symptoms urge leakage ('a strong desire to pass urine that results in leakage of urine before reaching the toilet' at least several times a month) and urgency ('a strength of urgency once you feel the need to pass urine that is typically very strong or overwhelming').

The baseline questionnaire contained questions on smoking habits, typical physical activity level over the previous year compared with people of a similar age, and frequency of participation in vigorous activities that make one sweaty or out of breath. In order to separate those who were physically unable to participate in vigorous activities from those who were able but chose not to participate, this question had an 'unable to participate' category.

Height and weight were used to calculate body mass index (BMI), which was categorised as underweight (BMI $<20 \mathrm{~kg} \mathrm{~m}^{-2}$ ), acceptable weight $\left(\mathrm{BMI}=20-25 \mathrm{~kg} \mathrm{~m}^{-2}\right.$ ), overweight $\left(25<\mathrm{BMI} \leq 30 \mathrm{~kg} \mathrm{~m}^{-2}\right)$ or obese (BMI
$>30 \mathrm{~kg} \mathrm{~m}^{-2}$ ). The number of $\mathrm{OAB}$ cases with BMI $<20 \mathrm{~kg} \mathrm{~m}^{-2}$ was very small $(n=5)$; therefore categories for underweight and acceptable body weight were combined.

\section{Food-frequency questionnaire}

The FFQ used ${ }^{13}$ was developed and validated by the UK arm of the European Prospective Investigation of Cancer. It contained questions on the frequency of consumption of 130 food and drink items, each with a choice of nine frequencies ranging from 'never or less than once a month' to 'six or more times per day'. Preparation of the data for analysis is described in detail in an earlier paper $^{10}$. Briefly, intakes of a number of food groups were computed by aggregating different food items and then divided into categories (usually quintiles or tertiles) depending on the data distribution of each food group in the cohort. There were also questions on frequency of consumption of a number of drinks. Total daily fluid intake $\left(\mathrm{ml} \mathrm{day}^{-1}\right)$ was estimated using volumes assigned to the drinks in the questionnaire. The data were processed to obtain total energy $\left(\mathrm{kJ} \mathrm{day}^{-1}\right)$ and nutrient intakes by assigning portion weights and representative food codes to the food items in the questionnaire ${ }^{13}$. This provided a value for total intake of alcohol ( $\mathrm{g}$ ethanol day $\left.^{-1}\right)$.

\section{Missing values}

Although the individual food items generally had small amounts of missing data (less than $2 \%$ ), summing food items to form food groups resulted in a high percentage of missing data for some food groups. Therefore, where less than $20 \%$ of the items forming a food group were missing, values for the missing items were imputed using the mean intake of the non-missing items and the imputed values were used in the calculation of the food groups. All analyses used the imputed values of the food groups, although repeating the analysis without imputation did not substantially alter the results.

\section{Statistical analysis}

Logistic regression models were used to examine the association of individual food groups, drinks and lifestyle factors measured at baseline with onset over one year of $\mathrm{OAB}$ in the men who had reported no OAB symptoms at baseline.

Univariate analyses of food groups were adjusted for age and total energy intake $\left(\mathrm{kJ} \mathrm{day}^{-1}\right)$ to control for confounding and to minimise variation due to general underreporting or overreporting of consumption. Analyses of drinks were adjusted for age and total fluid intake $\left(\mathrm{ml} \mathrm{day}^{-1}\right)$. Analyses of non-dietary lifestyle factors were adjusted for age and the two physical activity variables were additionally adjusted for physical functioning. This was assessed using the Short Form-36 (SF-36) instrument ${ }^{14}$ and divided into quartiles for analysis. 
All factors associated with $\mathrm{OAB}$ in the univariate analyses $(P<0.10)$ were entered into a multivariate model. Backward stepwise techniques were used to build the final model, with likelihood ratio tests used to determine significance. Because the urinary voiding symptoms of bladder outlet obstruction (BOO) are highly associated with $\mathrm{OAB}^{2}$, and with some of the lifestyle factors being studied $^{15-17}$, the multivariate model was rerun with an additional adjustment for signs of $\mathrm{BOO}$ at baseline. The number of urinary voiding symptoms reported at baseline was used as an indicator of BOO, using five voiding symptoms defined by the International Continence Society $^{1}$ (straining to void, intermittent stream, slow stream, hesitancy and incomplete emptying, all reported with a frequency of at least several times a month).

\section{Results}

The prevalence of $\mathrm{OAB}$ at baseline was $9.4 \%$ and increased with age (40-49 years: 4.4\%; 50-59 years: $7.2 \%$; 60-69 years: $8.4 \%$; 70-79 years: $16.7 \%$; 80 years + : 24\%). There were 4925 men without OAB at baseline, of whom 4382 (89.0\%) had information on OAB status at the one-year follow-up. The number of new cases over one year of follow-up was 233 (an incidence rate of 5.3\%). The incidence rate increased with age until the top age group ( $40-49$ years: $2.7 \% ; 50-59$ years: $4.3 \% ; 60-69$ years: $5.9 \%$; $70-79$ years: $9.3 \%$; 80 years $+: 7.6 \%)$.

In the univariate analyses of food groups and drinks (Tables 1 and 2), beer consumption was associated with a reduced risk of $\mathrm{OAB}$ onset at all levels of intake, compared with those who never/rarely drank beer. The negative trend in the results was highly significant $(P<0.001)$. The only food group that showed some association with $\mathrm{OAB}$ onset was potato consumption $(P=0.05)$, where the highest level of intake was associated with an increased risk of onset. Total intakes of energy $\left(\mathrm{kJ} \mathrm{day}^{-1}\right)$ and fluid $\left(\mathrm{ml} \mathrm{day}^{-1}\right)$ were not associated with OAB onset (results not shown).

After adjustment for physical functioning, physical activity was associated with $\mathrm{OAB}$ onset $(P=0.03)$, with responders who described themselves as more active than others of their age tending to show a reduced risk of OAB onset (Table 3). Overall, the participation in vigorous activity was significantly associated with onset $(P=0.003)$. However, the individual odds ratios only showed an increased risk in those who were unable to take part, while the two groups who reported some regular vigorous activity (1-2 and 3+ times a week) showed no difference in $\mathrm{OAB}$ onset. Smoking was not associated with $\mathrm{OAB}$ onset. The overall association with the obesity index was not significant $(P=0.11)$, although the obese group (BMI $>30 \mathrm{~kg} \mathrm{~m}^{-2}$ ) may be more likely to experience onset of symptoms (OR 1.62; 95\% CI 1.04-2.52).

In the multivariate model (Table 4 ) the association with beer remained highly significant $(P<0.001)$ and the
Table 1 Univariate analysis of food groups associated with onset of overactive bladder over one year in men without symptoms at baseline

\begin{tabular}{|c|c|c|c|}
\hline $\begin{array}{l}\text { Frequency } \\
\text { of intake of } \\
\text { average portion }\end{array}$ & $\begin{array}{l}\text { No. of onset } \\
\text { cases }\end{array}$ & OR $(95 \% \mathrm{Cl})^{*}$ & $P$-value \\
\hline \multicolumn{4}{|c|}{ Total vegetables $\dagger$} \\
\hline $0-2 /$ day & 49 & 1.00 & \\
\hline 3/day & 53 & $1.13(0.76-1.69)$ & 0.82 \\
\hline 4/day & 48 & $1.15(0.76-1.74)$ & \\
\hline 5/day & 28 & $0.91(0.56-1.47)$ & \\
\hline$\geq 6 /$ day & 46 & $1.15(0.75-1.77)$ & \\
\hline \multicolumn{4}{|l|}{ Potatoes } \\
\hline $0-5 /$ week & 71 & 1.00 & \\
\hline $6-7 /$ week & 56 & $1.05(0.72-1.55)$ & 0.05 \\
\hline$\geq 8 /$ week & 105 & $1.40(1.00-1.97)$ & \\
\hline \multicolumn{4}{|l|}{ Fruit } \\
\hline $0-5 /$ week & 46 & 1.00 & \\
\hline 6-9/week & 32 & $0.77(0.48-1.22)$ & 0.65 \\
\hline $10-14 /$ week & 52 & $1.08(0.72-1.64)$ & \\
\hline $15-21 /$ week & 48 & $0.99(0.65-1.51)$ & \\
\hline$\geq 22 /$ week & 44 & $0.94(0.61-1.46)$ & \\
\hline \multicolumn{4}{|l|}{ All meat† } \\
\hline $0-5 /$ week & 42 & 1.00 & \\
\hline $6-8 /$ week & 51 & $0.84(0.54-1.31)$ & 0.18 \\
\hline $9-10 /$ week & 35 & $0.95(0.59-1.52)$ & \\
\hline $11-13 /$ week & 43 & $1.17(0.75-1.83)$ & \\
\hline$\geq 14 /$ week & 56 & $1.38(0.88-2.15)$ & \\
\hline \multicolumn{4}{|l|}{ Fish } \\
\hline $0-1 /$ week & 65 & 1.00 & \\
\hline 2/week & 76 & $1.03(0.73-1.45)$ & 0.73 \\
\hline$\geq 3 /$ week & 81 & $0.91(0.64-1.28)$ & \\
\hline \multicolumn{4}{|l|}{ Cereal products } \\
\hline$<$ Weekly & 52 & 1.00 & \\
\hline 1/week & 67 & $1.19(0.81-1.73)$ & 0.40 \\
\hline 2/week & 47 & $1.08(0.71-1.63)$ & \\
\hline$\geq 3 /$ week & 56 & $0.86(0.57-1.30)$ & \\
\hline \multicolumn{4}{|c|}{ Breakfast cereals } \\
\hline < Daily & 118 & 1.00 & \\
\hline$\geq$ Daily & 108 & $1.04(0.79-1.37)$ & 0.77 \\
\hline \multicolumn{4}{|c|}{ Dairy \& egg products } \\
\hline $0-3 /$ week & 41 & 1.00 & \\
\hline 4-5/week & 51 & $1.19(0.78-1.82)$ & 0.77 \\
\hline $6-7 /$ week & 41 & $0.93(0.59-1.46)$ & \\
\hline $8-10 /$ week & 42 & $0.93(0.59-1.46)$ & \\
\hline$\geq 11 /$ week & 48 & $1.04(0.66-1.64)$ & \\
\hline \multicolumn{4}{|l|}{ Milk } \\
\hline$\leq \frac{1}{4}$ pint day & 39 & 1.00 & \\
\hline 1/2 pint/day & 78 & $1.09(0.73-1.62)$ & 0.86 \\
\hline $3 / 4$ pint/day & 44 & $1.12(0.72-1.76)$ & \\
\hline$\geq 1 \mathrm{pint} /$ day & 48 & $0.96(0.62-1.49)$ & \\
\hline \multicolumn{4}{|l|}{ Breads } \\
\hline $0-2 /$ day & 97 & 1.00 & \\
\hline$\geq 3 /$ day & 120 & $1.06(0.79-1.41)$ & 0.70 \\
\hline \multicolumn{4}{|c|}{ Sweets and snacks } \\
\hline $0-1 /$ day & 58 & 1.00 & \\
\hline $2-3 /$ day & 54 & $0.82(0.56-1.21)$ & 0.67 \\
\hline $4-5 /$ day & 36 & $0.80(0.51-1.24)$ & \\
\hline $6-7 /$ day & 38 & $1.02(0.66-1.58)$ & \\
\hline$\geq 8 /$ day & 45 & $0.99(0.63-1.57)$ & \\
\hline
\end{tabular}

$\mathrm{OR}$ - odds ratio; $\mathrm{Cl}$ - confidence interval.

${ }^{*}$ Adjusted for age and total energy intake $\left(\mathrm{kJ} \mathrm{day}^{-1}\right)$.

†No significant association with overactive bladder and vegetable subgroups (legumes: $P=0.29$, brassica: $P=0.35$; other vegetables: $P=0.96$ ) and meat subgroups (chicken: $P=0.38$; red meat: $P=0.23$; processed meat: $P=0.29$ ).

association with potatoes approached significance $(P=0.05)$. The association with vigorous activity remained significant, and, as in the univariate analysis, the increased risk only occurred in the group who were 
Table 2 Univariate analysis of drinks associated with onset of overactive bladder over one year in men without symptoms at baseline

\begin{tabular}{|c|c|c|c|}
\hline $\begin{array}{l}\text { Frequency of } \\
\text { intake of } \\
\text { average portion }\end{array}$ & $\begin{array}{c}\text { No. of } \\
\text { onset cases }\end{array}$ & OR $(95 \% \mathrm{Cl})^{*}$ & $P$-value \\
\hline \multicolumn{4}{|l|}{ Tea } \\
\hline $0-2 /$ day & 41 & 1.00 & \multirow{4}{*}{0.12} \\
\hline 3/day & 71 & $1.13(0.76-1.68)$ & \\
\hline $4-5 /$ day & 68 & $1.26(0.85-1.89)$ & \\
\hline$\geq 6 /$ day & 51 & $1.64(1.07-2.53)$ & \\
\hline \multicolumn{4}{|l|}{ Coffee } \\
\hline < Daily & 75 & 1.00 & \multirow{4}{*}{0.24} \\
\hline 1-2/day & 60 & $0.94(0.66-1.34)$ & \\
\hline 3/day & 59 & $0.81(0.57-1.14)$ & \\
\hline$\geq 4 /$ day & 26 & $0.64(0.40-1.02)$ & \\
\hline \multicolumn{4}{|l|}{ Wine } \\
\hline Never/rarely & 90 & 1.00 & \multirow{3}{*}{0.78} \\
\hline $1-4 /$ month & 61 & $0.92(0.65-1.28)$ & \\
\hline > Weekly & 79 & $0.90(0.66-1.23)$ & \\
\hline \multicolumn{4}{|l|}{ Beer } \\
\hline Never/rarely & 88 & 1.00 & \multirow{4}{*}{$<0.001$} \\
\hline $1-4 /$ month & 56 & $0.72(0.51-1.03)$ & \\
\hline 2-6/week & 65 & $0.66(0.47-0.94)$ & \\
\hline$\geq$ Daily & 23 & $0.38(0.24-0.61)$ & \\
\hline \multicolumn{4}{|l|}{ Spirits/sherry/port } \\
\hline Never/rarely & 121 & 1.00 & \multirow{3}{*}{0.17} \\
\hline $1-4 /$ month & 52 & $0.80(0.57-1.11)$ & \\
\hline$>$ Weekly & 59 & $0.76(0.55-1.05)$ & \\
\hline \multicolumn{4}{|l|}{ Fruit juice } \\
\hline$<$ Weekly & 82 & 1.00 & \multirow{3}{*}{0.53} \\
\hline 1/week & 48 & $0.92(0.63-1.33)$ & \\
\hline 2-6/week & 49 & $1.20(0.83-1.74)$ & \\
\hline$\geq$ Daily & 52 & $0.91(0.64-1.31)$ & \\
\hline \multicolumn{4}{|l|}{ Fizzy drinks } \\
\hline$<$ Weekly & 96 & 1.00 & \multirow{4}{*}{0.86} \\
\hline $1 /$ week & 41 & $1.01(0.69-1.48)$ & \\
\hline 2-6/week & 50 & $1.17(0.81-1.68)$ & \\
\hline$\geq$ Daily & 36 & $1.08(0.72-1.62)$ & \\
\hline
\end{tabular}

OR - odds ratio; $\mathrm{Cl}$ - confidence interval.

${ }^{*}$ Adjusted for age and total fluid intake $\left(\mathrm{ml} \mathrm{day}^{-1}\right)$.

unable to take part, suggesting that the association with $\mathrm{OAB}$ is related to morbidity and disability in this group. Self-assessment of typical physical activity level was no longer significant. Rerunning the multivariate model with additional adjustment for the number of voiding symptoms at baseline did not substantially alter the overall results.

Values for total alcohol intake ( $\mathrm{g}$ ethanol day ${ }^{-1}$ ) were available and a logistic regression was run to look at its association with OAB onset (adjusting for age). The results showed a highly significant negative trend $(P<0.001)$, with a reduced risk of OAB onset at all levels of alcohol intake compared with those who seldom/never drank alcohol (g ethanol day ${ }^{-1}$, OR (95\% CI): 0 to $<5$, 0.64 (0.42$0.97)$; $\geq 5$ to $<10,0.54(0.34-0.86)$; $\geq 10$ to $<20,0.53$ (0.34-0.83); $\geq 20,0.44(0.28-0.70)$ ). Inclusion of alcohol in the multivariate model reduced the significance of the association of beer with $\mathrm{OAB}$ onset $(P=0.02)$ (Table 4).

\section{Discussion}

The study provides no evidence that diet is associated with $\mathrm{OAB}$ onset in men, with the possible exception of
Table 3 Univariate analysis of non-dietary lifestyle factors associated with onset of overactive bladder over one year in men without symptoms at baseline

\begin{tabular}{|c|c|c|c|}
\hline Lifestyle category & $\begin{array}{c}\text { No. of } \\
\text { onset cases }\end{array}$ & $\begin{array}{c}\text { OR } \\
(95 \% \mathrm{Cl})^{*}\end{array}$ & $P$-value \\
\hline \multicolumn{4}{|c|}{ Physical activity compared with others of same age $\dagger$} \\
\hline More active & 112 & $0.76(0.54-1.06)$ & 0.03 \\
\hline Same level of activity & 61 & 1.00 & \\
\hline Less active & 57 & $1.29(0.86-1.95)$ & \\
\hline \multicolumn{4}{|l|}{ Vigorous activity† } \\
\hline $\begin{array}{l}\text { Physically unable } \\
\text { to participate }\end{array}$ & 43 & $2.27(1.45-3.56)$ & 0.003 \\
\hline $\begin{array}{l}\text { Never/seldom } \\
\text { participate }\end{array}$ & 61 & 1.00 & \\
\hline $1-2 /$ week & 64 & $1.18(0.81-1.71)$ & \\
\hline$\geq 3 /$ week & 62 & $1.00(0.68-1.48)$ & \\
\hline \multicolumn{4}{|l|}{ Smoking status } \\
\hline Never smoked & 71 & 1.00 & \\
\hline Ex-smoker & 129 & $0.99(0.73-1.34)$ & 1.00 \\
\hline Current smoker & 32 & $0.98(0.64-1.51)$ & \\
\hline \multicolumn{4}{|l|}{ Obesity index } \\
\hline $\begin{array}{l}\text { Under- and acceptable } \\
\text { weight }\end{array}$ & 79 & 1.00 & \\
\hline Overweight & 98 & $1.19(0.88-1.62)$ & 0.11 \\
\hline Obese & 29 & $1.62(1.04-2.52)$ & \\
\hline
\end{tabular}

OR - odds ratio; $\mathrm{Cl}$ - confidence interval.

* Adjusted for age.

†Adjusted for physical functioning (SF-36).

potatoes, where there was a weak association. There was a strong negative association with beer consumption, and this was independent of the total level of alcohol intake.

Most population studies on alcohol and incontinence are cross-sectional in design and provide conflicting results ${ }^{9,18,19}$. The problem with cross-sectional analysis is that it is not possible to conclude whether an association is causal. For example, OAB cases are likely to cut down on beer intake in order to reduce their symptoms. The present study, however, was longitudinal in design, and the negative associations we observed with beer and alcohol may therefore indicate the presence of a protecting factor. Although the prospective design of the study provides some confidence in the association being causal, we cannot dismiss the possibility that it may represent part of an effect. For example, chronic ill health, which is linked to $\mathrm{OAB}$, may result in abstinence from beer and other alcoholic drinks before the onset of OAB symptoms become apparent. In addition, people with developing OAB symptoms may avoid alcohol because of its diuretic properties.

The results show that both beer and total alcohol are independently and negatively associated with OAB onset, suggesting that non-alcoholic ingredients in beer may be important in addition to the alcohol content. The absence of an association with total fluid intake suggests that the volume of beer is probably not an important factor. Alcohol has both chronic and acute effects on the body. Animal studies on stimulated bladder muscle strips reported reduced contractility of the detrusor and urethra with acute administration of ethanol ${ }^{20,21}$, while studies on chronic exposure have shown both increased and 
Table 4 Multivariate analysis of factors associated with onset of overactive bladder over one year in men without symptoms at baseline

\begin{tabular}{|c|c|c|c|c|}
\hline Lifestyle category & OR $(95 \% \mathrm{Cl})^{*}$ & $P$-value & OR $(95 \% \mathrm{Cl}) \dagger$ & $P$-value \\
\hline \multicolumn{5}{|l|}{ Beer } \\
\hline Never/rarely & 1.00 & & 1.00 & \\
\hline $1-4 /$ month & $0.68(0.46-0.98)$ & 0.0001 & $0.81(0.50-1.30)$ & 0.02 \\
\hline $2-6 /$ week & $0.69(0.49-1.00)$ & & $0.88(0.53-1.44)$ & \\
\hline$\geq$ Daily & $0.32(0.19-0.54)$ & & $0.36(0.18-0.73)$ & \\
\hline \multicolumn{5}{|l|}{ Vigorous activity } \\
\hline Unable to participate & $2.18(1.37-3.48)$ & & $2.18(1.34-3.55)$ & \\
\hline Never/seldom participate & 1.00 & 0.007 & 1.00 & 0.01 \\
\hline $1-2 /$ week & $1.26(0.85-1.86)$ & & $1.24(0.83-1.86)$ & \\
\hline$\geq 3 /$ week & $0.99(0.66-1.48)$ & & $1.00(0.66-1.51)$ & \\
\hline \multicolumn{5}{|l|}{ Potatoes } \\
\hline $0-5 /$ week & 1.00 & 0.05 & 1.00 & 0.10 \\
\hline $6-7 /$ week & $1.08(0.73-1.60)$ & & $1.13(0.75-1.69)$ & \\
\hline$\geq 8 /$ week & $1.48(1.05-2.07)$ & & $1.45(1.02-2.07)$ & \\
\hline
\end{tabular}

OR - odds ratio; $\mathrm{Cl}$ - confidence interval.

${ }^{*}$ Adjusted for age, physical functioning (SF-36), energy ( $\mathrm{kJ}$ day ${ }^{-1}$ ) and fluid $\left(\mathrm{ml} \mathrm{day}^{-1}\right)$.

$\dagger$ Additional adjustment of daily alcohol intake (g ethanol day ${ }^{-1}$ ).

decreased contractility of the detrusor muscle 22,23 . Acute alcohol consumption causes a transient decrease in circulating testosterone levels ${ }^{24}$, and an increase in circulating oestrogens in men $^{25}$, and sex hormones have been shown to cause relaxation of certain smooth muscle types by suppressing calcium influx ${ }^{26}$. However, population studies on chronic moderate alcohol intake and testosterone concentration have reported conflicting results $^{27}$.

Beers are a relatively good source of folate and vitamin $\mathrm{B}_{6}$, and epidemiological studies have related low intakes of $\mathrm{B}_{6}$ to high plasma homocysteine ${ }^{28}$. This has been associated with cardiovascular ${ }^{29}$ and neurodegenerative disease ${ }^{30}$, and population studies have shown an inverse relationship between beer consumption and plasma homocysteine $\mathrm{s}^{31}$. Beers also contain a number of biologically active non-nutrients. Some of these could affect the contractile properties of the detrusor muscle, for example by acting as $\beta_{2}$ adrenoceptor agonists or muscarinic antagonists. Phyto-oestrogens are present in hops and barley $^{32}$ and the isoflavonoid genistein, present in beer, relaxes the contractility of the rabbit detrusor muscle by suppressing calcium influx through the calcium channels of smooth muscle membrane ${ }^{26}$.

The only food group showing a possible association with $\mathrm{OAB}$ onset was potatoes, where there was a positive association approaching significance $(P<0.05)$. The fact that only the highest level of intake was associated with an increased risk possibly suggests that intake of some 'toxic ingredient' at this level of consumption may be important. For example, potatoes when green contain solanine, a glycoalkaloid that inhibits the action of neurotransmitters $^{33}$, although it is very unlikely that the present level of intake had a toxic effect. Alternatively, a high potato intake may be an indicator of a diet type possibly associated with an increased risk of $\mathrm{OAB}$ onset; such as a high fat intake resulting from a 'fast-food diet' containing a lot of chips. In addition, the possibility of the association with potatoes occurring by chance cannot be ruled out, as the association is weak, and the possibility of finding an association by chance increases with the number of statistical tests being carried out.

Sex differences in pathophysiological mechanisms for $\mathrm{OAB}$ may account for the differences in results we obtained in our earlier analyses on women ${ }^{10}$. Smoking and carbonated drinks were positive risk factors in the women, and the results on diet in women suggested that three of the food groups might have a protective role. Beer consumption was not associated with $\mathrm{OAB}$ onset in women. Being overweight or obese were both significant risk factors for $\mathrm{OAB}$ onset in women, but there was little association in men. Most epidemiological studies on obesity and incontinence have been conducted among women, and have shown obesity to be a risk factor for both urge and stress incontinence ${ }^{7,34}$. Two studies that did include men showed obesity to be a risk factor in women but not men ${ }^{9,18}$. Hormonal differences between men and women may account for the some of the differences in results. For example, the increased risk of OAB onset we observed with smoking in women could be related to an anti-oestrogenic effect of smoking on the bladder or uethra ${ }^{35}$.

Differences in lifestyle between men and women exist, and could contribute to the differences in their results. The main difference in lifestyle was alcohol consumption, particularly that of beer. Total alcohol consumption was much lower in the women and $75 \%$ of the women never or rarely drank beer compared with $25 \%$ of the men. It is also possible that the number of male cases did not provide sufficient power for some differences to be detected. Despite original sample sizes being the same, the number of incident cases in the analysis on men was smaller than in the analysis on women ( 233 vs. 429). Reasons for this were the lower incidence rate of $\mathrm{OAB}$ in men $(5.3 \%$ vs. $8.3 \%)$, the lower response rates in men at all stages of the study (e.g. $60.5 \%$ vs. $65 \%$ at baseline) and a greater 
percentage of the original male sample being ineligible due to out-of-date records ( $9.3 \%$ vs. 5.0\%).

In men, factors possibly associated with $\mathrm{OAB}$ onset need to be interpreted with care, since the urinary voiding symptoms of BOO, usually the result of benign prostatic obstruction, often coexist with, and may be a cause of, $\mathrm{OAB}^{2}$. There is some evidence that BOO induces alterations in the contractile properties and innervation of the bladder, but there is not a straightforward causal relationship between $\mathrm{BOO}$ and $\mathrm{OAB}^{2}$. Population studies on benign prostatic obstruction and on $\mathrm{BOO}$ have identified a number of lifestyle risk factors, including smoking and diet ${ }^{16,36}$. The published studies on alcohol and $\mathrm{BOO}$ are conflicting, although interestingly two studies have shown alcohol to have a protective effect ${ }^{36,37}$ and others a protective effect specifically for beer ${ }^{38,39}$. The adjustment we made for the number of urinary voiding symptoms reported at baseline did not substantially alter the results of the multivariate model. However, the use of voiding symptoms as an indicator of BOO needs validating and therefore we cannot confidently dismiss the argument that the observed associations of beer and alcohol with $\mathrm{OAB}$ onset are in fact operating via an effect on BOO.

The results must be considered in light of the strengths and limitations of the study design. As the analysis was carried out on members of the sample who had completed all three postal questionnaires, the issue of possible nonresponse bias is important. At baseline there was little indication of non-response bias in terms of urinary symptoms ${ }^{11}$. The poorer response to the FFQ and followup questionnaire by the elderly and by those with poorer health is predictable; it could result in a greater loss of incident cases in these groups. The overall outcome is likely to be a reduction in the variability of the data, which could possibly limit our ability to detect genuine associations.

The fact that the FFQ used was validated in a UK population similar to our own ${ }^{13}$ strengthens our confidence in the dietary data. There is an acknowledged tendency with FFQs for overreporting of certain foods and by certain population groups; in the present study, any overreporting that does occur is magnified in certain food groups, because the values are totals of lists of items. However, despite finding a two-fold difference in total vegetable intake when determined from a list of vegetables compared with a single question, Amanatidis et $a l .{ }^{40}$ showed that the effect on ranking of individuals was small. Despite measurement errors, FFQs with an acceptable validity and reliability can be used in large epidemiological studies to rank and categorise individuals to conduct within-group analysis ${ }^{41}$. Random measurement errors that do occur will reduce, not increase, the chance of detecting associations and are therefore likely to underestimate the strength of any associations found. Lifestyle measures such as diet, smoking and physical activity are accepted confounding factors in any analysis on alcohol intake. These lifestyle factors were included in the present analysis, so we can be reasonably confident that the strong association with beer is not due to confounding. A possible confounding effect of occupational social class could not be considered, as the necessary data were not available. However, adjustment for housing tenure, car ownership and employment status did not alter the results for the association with beer.

The present longitudinal study is the first to have considered the association between diet and $\mathrm{OAB}$ onset in men. There is no evidence that the food groups studied, with the possible exception of potatoes, play a role in the aetiology of $\mathrm{OAB}$ in men. The results of this longitudinal study suggest that an increased consumption of beer may possibly play a protective role. Beer may contain an ingredient that affects the contractile properties of the detrusor muscle, and further work is needed to confirm the results and investigate whether any association with beer is due to alcohol or a non-alcoholic ingredient. In future work, cases need to be identified using stricter clinical indicators of $\mathrm{OAB}$ status, with the additional ability to accurately identify cases of BOO.

\section{Acknowledgements}

This work was funded by the Medical Research Council. The authors thank all members of the Leicestershire MRC Incontinence Study Group for their contributions, Ailsa Welch (The Institute of Public Health, University of Cambridge) for advice with collecting and processing the FFQ data and Ruth Elliott (Department of Obstetrics and Gynaecology, University of Leicester) for help discussing the literature. We also thank the general practitioners of Leicestershire and Rutland who gave their support to the study and the members of the public who participated.

\section{References}

1 Abrams P, Cardozo L, Fall M, Griffiths D, Rosier P, Ulmsten U, et al. The standardisation of terminology of lower urinary tract function: report from the Standardisation Sub-committee of the International Continence Society. Neurourology and Urodynamics 2002; 21: 167-78.

2 Abdel-Aziz KF, Lemack G. Overactive bladder in the male patient: bladder, outlet, or both? Current Urology Reports 2002; 3: 445-51.

3 De Groat WC. A neurologic basis for the overactive bladder. Urology 1997; 50: 36-52.

4 Rana S, D'Amico F, Merenstein JH. Relationship of vitamin B-12 deficiency with incontinence in older people. Journal of the American Geriatric Society 1998; 46: 931-2.

5 Brading AF. A myogenic basis for the overactive bladder. Urology 1997; 50: 57-67.

6 Brown JS, Grady D, Ouslander JG, Herzog AR, Varner E, Posner SF. Prevalence of urinary incontinence and associated risk factors in post-menopausal women. Obstetrics and Gynecology 1999; 94: 66-70.

7 Moller LA, Lose G, Jorgensen T. Risk factors for lower urinary tract symptoms in women 40 to 60 years of age. Obstetrics and Gynecology 2000; 96: 446-51. 
8 Muscatello DJ, Rissel C, Szonyi G. Urinary symptoms and incontinence in an urban community: prevalence and associated factors in older men and women. Internal Medicine Journal 2001; 31: 151-60.

9 Bortolotti A, Bernardini B, Colli E, Di Benedetto P, Nacci GG, Landoni $\mathrm{M}$, et al. Prevalence and risk factors for urinary incontinence in Italy. European Urology 2000; 37: 30-5.

10 Dallosso HM, McGrother CW, Matthews RJ, Donaldson MMK. The association of diet and other lifestyle factors with overactive bladder and stress incontinence: a longitudinal study in women. BJU International 2003; 92: 69-77.

11 Dallosso HM, Matthews RJ, McGrother C, Clarke M, Perry S, Shaw C, et al. An investigation into non-response bias in a postal survey on urinary symptoms. BJU International 2003; 91: $631-6$.

12 Perry S, Shaw C, Assassa P, Dallosso HM, Williams K, Brittain $\mathrm{KR}$, et al. An epidemiological study to establish the prevalence of urinary symptoms and felt need in the community: the Leicestershire MRC Incontinence Study. Journal of Public Health Medicine 2000; 22: 427-34.

13 Bingham SA, Welch A, McTaggart A, Mulligan A, Runswick S, Luben $\mathrm{R}$, et al. Nutritional methods in the European Prospective Investigation of Cancer in Norfolk. Public Health Nutrition 2001; 4: 847-58.

14 Ware JE, Snow KK, Kosinski M, Gandek B. SF-36 Health Survey Manual and Interpretation Guide. Boston, MA: The Health Institute, 1993.

15 Prezioso D, Catuogno C, Galassi P, D'Andrea G, Castello G, Pirritano D. Lifestyle in patients with LUTS suggestive of BPH. European Urology 2001; 40: 9-12.

16 Koskimaki J, Hakama M, Huhtala H, Tammela TL. Association of dietary elements and lower urinary tract symptoms. Scandinavian Journal of Urology and Nephrology 2000; 34: 46-50.

17 Platz EA, Kawachi I, Rimm EB, Colditz GA, Stampfer MJ, Willett WC, et al. Physical activity and benign prostatic hyperplasia. Archives of Internal Medicine 1998; 158: 2349-56.

18 Schmidbauer J, Temml C, Schatzl G, Haidinger G, Madersbacher S. Risk factors for urinary incontinence in both sexes - analysis of a health screening project. European Urology 2001; 39: 565-70.

19 Brown JS, Seeley DG, Fong J, Black DM, Ensrud KE, Grady D. Urinary incontinence in older women: who is at risk? Obstetrics and Gynecology 1996; 87: 715-21.

20 Ohmura M, Kondo A, Saito M. Effects of ethanol on responses of isolated rabbit urinary bladder and urethra. International Journal of Urology 1997; 4: 295-9.

21 Yokoi K, Ohmura M, Kondo A, Miyake K, Saito M. Effects of ethanol on in vivo cystometry and in vitro whole bladder contractility in the rat. Journal of Urology 1996; 156: 1489-91.

22 Knight GE, Brizzolara AL, Soediono PO, Karoon P, Burnstock G. Chronic ethanol-consumption affects cholinoceptor-mediated and purinoceptor-mediated contractions of the isolated rat bladder. Alcohol 1995; 12: 183-8.

23 Kim HJ, Moon H, Sohng I, Lee HW, Lee G, Lee JG. Effects of ethanol and its metabolite acetaldehyde on responses of the rat bladder. BJU International 1999; 83: 686-92.
24 Ida Y, Tsujimaru S, Nakamaura K, Shirao I, Mukasa H, Egami $\mathrm{H}$, et al. Effects of acute and repeated alcohol ingestion on hypothalamic-pituitary-gonadal and hypothalamic-pituitary-adrenal functioning in normal males. Drug and Alcohol Dependence 1992; 31: 57-64.

25 Couwenbergs CJ. Acute effects of drinking beer or wine on the steroid hormones of healthy men. Journal of Steroid Biochemistry 1988; 31: 467-73.

26 Ratz PH, McCammon KA, Altstatt D, Blackmore PF, Shenfeld OZ, Schlossberg SM. Differential effects of sex hormones and phytoestrogens on peak and steady state contractions in isolated rabbit detrusor. Journal of Urology 1999; 162: 1821-8.

27 Allen NE, Key TJ. Sex hormones and diet in men. Nutrition Research Reviews 2000; 13: 159-84.

28 Selhub J, Jacques PF, Wilson P, Rush D, Rosenberg IH. Vitamin status and intake as primary determinants of homocysteinemia in an elderly population. Journal of the American Medical Association 1993; 270: 2693-8.

29 Eikelboom JW, Lonn E, Genest J, Hankey G, Yusuf S. Homocysteine and cardiovascular disease: a critical review of the epidemiologic evidence. Annals of Internal Medicine 1999; 131: 363-75.

30 Diaz-Arrastia R. Homocysteine and neurologic disease. Archives of Neurology 2000; 57: 1422-7.

31 De Bree A, Verschuren WM, Blom HJ, Kromhout D. Association between B vitamin intake and plasma homocysteine concentration in the general Dutch population aged 20-65y. American Journal of Clinical Nutrition 2001; 73 : $1027-33$.

32 Lapcik O, Hill M, Hampl R, Wahala K, Adlercreutz H. Identification of isoflavonoids in beer. Steroids 1998; 63: 14-20.

33 Slanina P. Solanine (glycoalkaloids) in potatoes - toxicological evaluation. Food Chemistry and Toxicology 1990; 28: 759-61.

34 Mommsen S, Foldspang A. Body mass index and adult female urinary incontinence. World Journal of Urology 1994; 12: 319-22.

35 Baron JA. Smoking and estrogen-related disease. American Journal of Epidemiology 1984; 119: 9-22.

36 Platz EA, Rimm EB, Kawachi I, Colditz GA, Stampfer MJ, Willett WC, et al. Alcohol consumption, cigarette smoking, and risk of benign prostatic hyperplasia. American Journal of Epidemiology 1999; 149: 106-15.

37 Ellgring H, Seiler S, Perleth B, Frings W, Gasser T, Oertal W. Psychosocial aspects of Parkinson's disease. Neurology 1993; 43: S41-4.

38 Morrison AS. Risk factors for surgery for prostatic hypertrophy. American Journal of Epidemiology 1992; 135: $974-80$.

39 Chyou P, Nomura A. A prospective study of alcohol, diet, and other lifestyle factors in relation to obstructive uropathy. Prostate 1993; 22: 253-64.

40 Amanatidis S, Mackerras D, Simpson JM. Comparison of two frequency questionnaires for quantifying fruit and vegetable intake. Public Health Nutrition 2001; 4: 233-9.

41 Willett WC. Nutritional Epidemiology. New York: Oxford University Press, 1998. 